\title{
Sex Ratio Theory is a Contradiction, Not an Extension, of Kin Selection
}

\author{
Deby Cassill*
}

Department of Biology, USF St. Petersburg, St. Petersburg, Florida 33701, USA

\begin{abstract}
Kin selection and sex ratio theory employ gene-centric models with coefficients of relatedness to explain the evolution of altruism in the social Hymenoptera. Central to both theories is the fact that Hymenoptera organisms are haplodiploid, a condition that creates an asymmetry in relatedness among siblings. This paper exposes the fact that sex ratio theory is a contradiction, not an extension, of kin selection. In kin selection, Hamilton developed the coefficient of relatedness as a probability fraction. Hamilton's altruists must help a small number of close relatives or a large number of distant relatives to ensure that one copy of their altruistic genes are propagated into the next generation. In sex ratio theory, Trivers and Hare modeled the coefficient of relatedness as an arithmetic fraction rather than a probability fraction. As a result, their altruists help a large number of close relatives and a small number of distant relatives, the opposite of Hamilton's altruists. Gene-centric modelers must clarify which relatedness coefficient, arithmetic or probability, they are using to frame their predictions.
\end{abstract}

Keywords: Evolution, social insects, sociobiology, skew selection.

\section{INTRODUCTION}

Theories function as a framework for understanding and interpreting evolutionary processes. Because theories affect the way evolutionary biologists conduct their research, they must be closely scrutinized [1]. In this paper, we compare the predictions of kin selection [2] to sex ratio theory [3], and show that they are not complementary as currently assumed, but, in fact, produce opposing predictions about the behavior of altruists toward their relatives.

\section{KIN SELECTION}

In 1964, William Hamilton published a gene-centric model based on a coefficient of relatedness for the evolution of altruism which he called "inclusive fitness." Hamilton's model predicted that relatives might help each other based on the probability that they share genes from a common ancestor, a parent or grandparent. Eventually, his model became known as kin selection.

Kin selection assumes that altruistic and selfish behaviors of offspring are mutually exclusive. Thus, an offspring is either altruistic or selfish, but never both. According to Hamilton, if an altruist is unable to determine which of its many relatives shares its altruistic gene, then the altruist must 'play the odds' by saving a minimum number of relatives to ensure that one of them carries the gene for altruism.

To predict the minimum number of relatives an altruist must help, Hamilton employed Sewall Wright's kinship term, the coefficient-of-relatedness (Table 1). Hamilton then transformed the coefficient-of-relatedness decimals into probability fractions and asked: What is the probability that an altruist would share its altruistic gene with a relative (Table 1, Column 3)? The odds of sharing an altruistic gene

*Address correspondence to this author at the Department of Biology, USF St. Petersburg, St. Petersburg, Florida 33701, USA; Tel: (727) 873-4064; Fax: (727) 873-4526; E-mail: cassill@ mail.usf.edu with a relative differ depending on the relative's relationship to the altruist. For example, an altruist need help one twin, two full siblings, four half-siblings or eight cousins to be assured that one copy of its altruistic gene is replicated into the next generation. The point here is that, given a choice, an altruist is likely to help one twin, but not one cousin because there is only one chance in eight that the cousin shares its altruistic gene, therefore, it is predicted to help itself and hope it mates and produces offspring that carry its altruistic gene. The same is true among siblings. An altruist is more likely to help itself than one sibling. But if the altruist can help two siblings, Hamilton's model predicts that it will do so, as one of the siblings is likely to carry its altruistic gene.

If we convert the coefficient-of-relatedness from a decimal to an arithmetic fraction (Table 1, Column 3) and then reduce the arithmetic fraction to a probability fraction (Table 1, Column 4), we see that the denominator of the probability fraction dictates the minimum number of relatives that an altruist must help to assure that its copy of the altruistic gene is replicated into the next generation by the surviving relative. In other words, the probability fraction shows the "odds" of sharing an altruistic gene with another relative-1 chance in 2; 1 chance in $4 ; 1$ chance in 8 ; and so forth.

In a subsequent paper, Hamilton calculated relatedness coefficients based on inbreeding [4]. He calculated unusual relatedness fractions such as the .375 relatedness of siblings who have the same mother but different fathers where the fathers are brothers. In this case, the .375 relatedness coefficient is converted to an arithmetic fraction of $3 / 8$ and then reduced to a probability fraction of $1 / 2.67$ which translates into a " 1 chance in 2.67 " of two siblings sharing an altruistic gene-which correctly falls between " 1 chance in 2 " of full siblings and the " 1 chance in 4" for half siblings. Hamilton also calculated the relatedness among offspring produced from matings by siblings, which happens in termites. The coefficient of relatedness among offspring of siblings is .667 which converts into an arithmetic fraction of $2 / 3$ and then 
Table 1. Comparing Coefficients-of-Relatedness ("r") for Sex Ratio Theory and Kin Selection

\begin{tabular}{|c|c|c|c|}
\hline $\begin{array}{c}\text { (1) } \\
\text { Type of relative }\end{array}$ & $\begin{array}{c}\text { (2) } \\
\text { "ros decimal }\end{array}$ & $\begin{array}{c}\text { (3) } \\
\text { "r" as arithmetic fraction }\end{array}$ & $\begin{array}{c}\text { (4) } \\
\text { "rs probability fraction }\end{array}$ \\
\hline \hline $\begin{array}{c}\text { Twins } \\
\text { Clones }\end{array}$ & 1.0 & $1 / 1$ & $1 / 1$ \\
\hline $\begin{array}{c}\text { Haplodiploid } \\
\text { Sister to sister }\end{array}$ & 0.75 & $3 / 4$ & $1 / 1.33$ \\
\hline $\begin{array}{c}\text { Diploid } \\
\text { Full-siblings }\end{array}$ & 0.5 & $1 / 2$ & $1 / 2$ \\
\hline $\begin{array}{c}\text { Diploid } \\
\text { Half-siblings }\end{array}$ & 0.25 & $1 / 4$ & $1 / 4$ \\
\hline $\begin{array}{c}\text { Haplodiploid } \\
\text { Sister to brother }\end{array}$ & 0.25 & & $1 / 4$ \\
\hline
\end{tabular}

Column (1): Type of relative. Column (2): The coefficient of relatedness " $r$ " is displayed as a decimal. Relatedness of siblings in haplodiploid animals is asymmetrical. Column (3): " $\mathrm{r}$ " is displayed as an arithmetic fraction correctly reduced to the lowest common denominator. Column (4): " $\mathrm{r}$ " is displayed as a probability fraction correctly reduced to the lowest common numerator. The denominator represents the number of relatives that a Hamiltonian altruist should help.

reduces to a probability fraction of $1 / 1.5$ meaning that there is " 1 chance in 1.5 " of those offspring sharing an altruistic gene. The 1.5 chance correctly falls between that " 1 chance in 1" for twins and the "1 chance in 2 " for full siblings whose parents were not inbred siblings themselves.

Hamilton's altruist is constrained by the "odds" of sharing a gene with a relative. If an altruist helps fewer than two siblings, four half-siblings or eight cousins, then the altruistic gene will eventually go to extinction. In other words, Hamilton's altruist is limited to a minimum number of relatives that he can help. For the remainder of this paper, I ignored the fact that helping more than two siblings, four halfsiblings or eight cousins, which is allowed by Hamilton's Rule, violates the first principle of Hamilton's inclusive fitness [5].

Hamilton's kin selection model predicts the sex ratio of male and female offspring. For diploid species, Hamilton's altruistic sibling should help an unbiased sex ratio of siblings -1 sister and 1 brother; 2 sisters or 2 brothers. What about haplodiploid species? Recall that Hamilton's altruist helps only enough relatives to make sure that one copy of its genes gets into the next generation. By converting the coefficient-of-relatedness to an arithmetic fraction and then reducing that fractions to its lowest common numerator per Hamilton's probability construct, we find that sterile ants should help 1.3 fertile sisters for every 4 fertile brothers (Table $\mathbf{1}$, Column 4). This numeric 1.3 to 4 sex ratio reduces to a $1: 3$ female:male sex ratio, which is the opposite prediction of the Trivers and Hare sex ratio model. How did this happen?

\section{SEX RATIO THEORY}

Robert Trivers and Hope Hare [3] employed Hamilton's coefficient of relatedness to predict that sterile workers of the social Hymenoptera should produce a 3:1 female-biased sex ratio. How did Trivers and Hare construct a 3:1 female:male sex ratio for haplodiploid insects that is the inverse of Hamilton's 1:3 female:male sex ratio for haplodiploid insects.
The explanation is based on the fact that decimals can be reduced in two ways: arithmetic fractions and probability fractions. Trivers and Hare reduced relatedness decimals into arithmetic fractions. They neglected to complete the extra step to further reduce the fraction into a probability fractions as originally intended by Hamilton. In short, Trivers and Hare reduced relatedness decimals to the lowest common denominator (Table 1, Column 5) rather than the lowest common numerator. After standardizing the denominators, Trivers and Hare compared numerators to derive their 3:1 female-biased sex ratio.

How does their arithmetic fraction translate into altruistic behavior? A Trivers and Hare altruist is predicted to help 4 twins, 2 full siblings or 1 half-sibling (Table 1, column 5). Compare this to Hamilton's altruist who is predicted to help 1 twin, 2 full siblings or 4 half-siblings to ensure that its altruistic gene is replicated in the next generation (Table 1, column 3). This point bears reiteration. A Trivers and Hare altruist will help a larger number of close relatives, which is the inverse of Hamilton's altruist, who will help a smaller number of close relatives.

\section{OFFSPRING SKEW}

In summary, the probability construct of kin selection is the inverse of the arithmetic construct of sex ratio theory. What is an altruist to do? Perhaps a better question is, What is a theoretical biologist to do? I recommend that we set aside gene-centric models for a few years and work with models such as offspring skew $[5,6,8]$ that are rooted in natural selection. Offspring skew predicts that risky environments will select for breeders who not only overproduce offspring [7], but also "skew" offspring ability—producing a mix of altruistic and selfish offspring. By skewing offspring ability, breeders increase the probability that some of their offspring will survive the dual threats of predators and starvation. In other words, altruistic offspring are by nature's design disposable. They are sacrificed to predators to increase the probability that fertile offspring will survive to become the next generation of breeders. 
Offspring skew is a significant break from current individual selection, kin selection and group selection models which assume that, at birth, offspring survival is random [9]. Although politically incorrect, offspring skew (the idea that survival among offspring is biased at birth such that some are more likely to die young than others) passes the test of Occam's razor by providing a simple, natural selection solution to the myriad cases of altruism from ants to naked mole rats to humans.

\section{ACKNOWLEDGEMENTS}

The author wishes to thank two anonymous reviewers for constructive comments and the Publications Manager, Asna Shahid, for coordination and communication. This research was funded, in part, by an internal grant from USF St. Petersburg.

\section{REFERENCES}

Brooks, D.R.; Wiley, E.O. Evolution as entropy: Toward a unified theory of biology. University of Chicago Press: Chicago 1986.
[2] Hamilton, W.D. The genetical evolution of social behavior. $J$. Theor. Biol., 1964, 7, 1-16.

[3] Trivers, R.L.; Hare, H. Haplodiploidy and the evolution of the social insects. Science, 1976, 191, 249-263.

[4] Hamilton, W.D. Altruism and related phenomena, mainly in social insects. Ann. Rev. Ecol. Syst., 1972, 3, 193-232.

[5] Cassill, D.L. Why skew selection, a model of parental exploitation, should replace kin selection. J. Bioeconom., 2006, 8, 101-119. Available from: http://www.springerlink.com/content/63j12k7w561gr667)

[6] Cassill, D.L. The social gene. J. Bioeconom., 2005, 7, 73-84.

[7] Malthus, T. An essay on the principle of population. J. Johnson: London 1798.

[8] Cassill, D.L.; Watkins, A. The emergence of cooperative hierarchies through natural selection processes. J. Bioeconom., 2010, 12, 29-42. http://www.springerlink.com/openurl.asp?genre= article\&id=doi:10.1007/s10818-010-9080-y

[9] Cassill, D.L.; Kuriachan, I.; Vinson, S.B. A test of two skew models to explain cooperative breeding among unrelated individuals. $J$. Bioeconom., 2007, 9, 19-37.

(C) Deby Cassill; Licensee Bentham Open.

This is an open access article licensed under the terms of the Creative Commons Attribution Non-Commercial License (http://creativecommons.org/licenses/by-nc/3.0/) which permits unrestricted, non-commercial use, distribution and reproduction in any medium, provided the work is properly cited. 